\section{Deciphering Fake News: Navigating Today's News Standards}

\section{Christina Borst}

Junior, Strategic Communication \& Political Science

With Russian hacks, rigged elections, and faulty online social platforms consuming conversations and media attention on an almost daily basis, the topic of fake news has become more prevalent than ever before. Over the course of the last two years, with its breakthrough into mainstream society occurring around the 2016 presidential election, fake news has transformed into a phenomenon that has changed the way we consume media in the United States. However, fake news is not exclusive to today, with journalists such as Edward McKernon of Harper's Magazine covering the dangers of untrustworthy news as early as 1925 . McKernon discusses the difficulty of discerning between true and false information because of the fast rates at which news travels from person to person. Seeing that this was posited at a time in which online news did not exist is alarming considering today's news standards. ${ }^{1}$ Fake news extends beyond the perpetuation of rumors; turning what is false into the world's reality is just one of its perilous ramifications. Facebook's questionable role in perpetuating fake news to sway the 2016 presidential election results in favor of President Trump is a singular example that forces society to rethink the legitimacy of the information presented. ${ }^{2}$
When studied, fake news is defined as information appearing to be news content that differs in intent. In other words, those who create fake news do so with the purpose to deceive or misinform, framing stories to appear credible. The resurgence of fake news has brought about a need to study both the general knowledge of and ability to spot fake news. To study the pervasiveness of fake news, several research questions were used for guidance: What are the common understandings or misunderstandings of fake news and its perpetuation? What are the characteristics of individuals who are more apt to recognize fake news? Does an individual's level of political activism or civic engagement affect their ability to recognize fake news? It is crucial that the unit of analysis was the individual, since individuals hold responsibility in spreading fake news, especially via online platforms.

Between 2006 and 2017, the top one percent of fake news reached between 1,000 and 100,000 people, while true news stories seldom diffused to more than 1,000 people. Humans were found to have spread fake news at the same rate as bots. ${ }^{3}$ With the press being labeled as the de facto fourth estate, tasked with checking the powers of the three branches of government by exposing the truth, there are now worries over its own trustworthiness. Who will now be the greatest defenders of the truth? For the theoretical expectations of these research questions, it was hypothesized that the interviewees' understanding of fake news and accuracy in distinguishing real and fake news would be dependent on their news-reading habits. Those who engaged 
with news the most often and across the most platforms would be more likely to accurately discern between what is real news and what is fake news.. Additionally, those who had more experience with political activism and civic engagement, or had educational backgrounds relating to those areas, would be more accurate at this differentiation as well. These expectations derive from certain individuals having a higher affinity for current events, whether from their passions for activism or engagement, or the nature of their education or field demanding them to be "in-the-know." Since they engage with the news more often, it is assumed that they have gained a more refined sense of media literacy, which allows them to critically analyze and assess media.

The interviews consisted of two portions: the interview questions and a test in which interviewees were asked to differentiate between real and fake news headlines. Eight face-to-face interviews were conducted in a semi-structured format. The semi-structured interviews used the same questions in the same order but included room for the interviewees to expand more on their thoughts and ideas. With some structure in place, the topic was only restricted to some extent while still maintaining a standardization. The test portion was also asked in the same order and included ten different headlines, six of which were true and four of which were false stories. The interviewees were then each given a percentage score. The audio of each interview was recorded and later transcribed to detect patterns, similarities, and differences among the responses.

Questions were reviewed and adjusted if necessary after every interview.

All eight of the interviewees resided in the greater Philadelphia area, so they would be within the same media market and have an awareness of the same local news outlets. Interviewees \#1 through \#4 (category \#1) identified as students ages 18 to 22, and consisted of two males and two females. Interviewees \#1 and \#2 were political science college students and were selected to participate for their expected connections to activism and awareness of current events. Interviewee \#3 was an advertising college student, while interviewee \#4 was a recent high school graduate. The selection of interviewees \#3 and \#4 was of interest in order to compare educational differences in fields unrelated to civic engagement. On the other hand, interviewees \#5 through \#8 (category \#2) were ages 45 to 60 and well-established in their fields of work, three of who were women and one who was a male. Interviewee \#5 had a master's degree and actively worked as a campaign consultant. Interviewee \#6 worked in public relations with an industry focus outside of politics but still needed to have an awareness of current events. Interviewee \#7 worked in education, and interviewee \#8 was a mechanic, thus the only individual in this category without any formal college education. All of the interviewees were registered Democrats. Before delving into the interview questions, interviewees were asked to confirm basic demographic information, such as age, educational background, and political 
affiliation to ensure accurate analysis.

Questions and headlines from both portions of the interview process are included in the appendix.

The interviews began by asking the individuals if they considered themselves to be politically active and civically engaged outside of their studies or field of work. This question was designed to gauge how willing the interviewees were to volunteer in causes that they were not required to partake in, marking a distinct interest in civic engagement. A second question involving the last time interviewees voted in an election was incorporated to measure how often they took part in the most basic civic responsibility. They were then asked to talk about the frequency at which they engaged with the news. The word "engaged" was used to encompass the multidimensional methods that can be obtained, such as reading, watching, and listening on mediums including social media, online platforms, television, and radio. Interviewees were then asked through which of these mediums they engaged with news and to list specific examples of the news outlets they typically engage with, noting if any of these outlets centered on local news. Furthermore, they were asked how much of their news was obtained from social media, and if they consistently engaged with news that did not align with their beliefs. These questions were supposed to measure the critical concepts of political activism and affiliation and news engagement.

Responses to this set of questions were as predicted. Interviewees \#1 and \#2, who studied political science, talked about their involvement in political and civic activities other than their school work, including protesting and volunteering for Philadelphia campaigns. They also belonged to political organizations on their college campuses. All other interviewees noted that they did not mark themselves as politically active or civically engaged. Surprisingly, every interviewee answered that they voted in the 2018 Pennsylvania municipal primary, the state's most recent election. These results demonstrated a baseline interest in civic engagement, regardless of how the interviewees evaluated themselves. The only participants who engaged with the news everyday were interviewees \#1 and \#2 and \#5 and \#6, those who turn to news as a necessity in their studies or work. All participants listed highly partisan, liberal-leaning outlets for their go-to news sources, including the Washington Post, New York Times, CNN, MSNBC, and NPR. They each admitted that they were mostly unwilling to engage with news that did not already align with their political beliefs. As explained by interviewee \#4, "I trust the sources that align with my beliefs more. When I read news that is more conservative, I get agitated quickly."

The concept of trust was pinpointed as an overarching theme among the eight interviewees. When asked what the term fake news meant to them, it always came down to what they could and could not trust. When deciphering between real and fake news, all interviewees said they look at the source before any other factor. This method held especially true for news that was online or posted on social media. The news from 
the sources that they trusted the most had a significant partisan bias. When unsure of a source's trustworthiness, they turned to the wording of the headline, the URL of the article, and the visual format of the article and the coinciding website. An overall pattern was detected of how people usually recognize the difference between fake and real news, however, the tendency to give in to a partisan bias through confirmation bias and selective exposure was much more significant. Fundamentally, individuals are prone to only exposing themselves to news that confirms the beliefs they already hold, motivated to feel correct in their political positions. ${ }^{4}$ Individuals assume that the news outlets that they habitually engage with are accurate because these stories align with what they already think is true. Still, they may not be thinking critically about these sources that they assume are always accurate, which could lend to the perpetuation of partisan fake news.

For the second portion of the interview process, interviewees were tested on their knowledge of fake news. Ten headlines from online articles published in 2016 to the present were read aloud. Interviewees were only given the headline and could not depend on visual cues. In the set were six real news articles: "Climate Change can be Stopped by Turning Air Into Gasoline," "Two Peacocks that Escaped Philadelphia Zoo Found, Search for Last Continues," "Jet-Powered Suit Sets New Fastest Speed as World Records Tumble," "Trump Admin Expected to Suspend August US-South Korea Military Drill as Pentagon Scrambles," "Trump Answers Kim
Kardashian's Clemency Plea," and "George H.W. Bush Hospitalized One Day After the Funeral for his Wife, Barbara." The headlines of the four fake news articles included: "Social Security Called Federal Benefit Payment," "Pope Francis Shocks World, Endorses Donald Trump," "AG Sessions Defends Separating Immigrant Families by Citing Senate Confirmation Vote," and "Pope Endorses Sanders for President." The selected articles were chosen from a variety of sources with different partisan slants and hit on different subject areas, but deliberately emphasized political current events. Articles were checked on Snopes, a fact-checking website, for accuracy.

Interviewees \#1 and \#2 had the highest scores, each earning an $80 \%$. Interviewee $\# 5$ had the next highest score at $70 \%$. Interviewees \#3, \#4, \#6, and \#7 earned $50 \%$, with interviewee $\# 8$ scoring the least at $30 \%$. Given these scores, a clear pattern is revealed about how the frequency at which one engages with the news affects their ability to spot fake news. Those who engaged with the news most had political backgrounds and scored the best on the test. There is not enough data to conclude that political activism and civic engagement correlate with a better understanding of fake news. Even so, those who engaged with news the most frequently and widely did perform markedly better than the others. Interviewee \#8's poor performance relates to this trend as well, as this participant lacked a formal college education. Interviewee's \#1, $\# 2$, \#5, and \#6 all mentioned that they sometimes research news sources when they 
are unsure if they are real, demonstrating a willingness to dig further for the truth. There were no connections for age and gender.

Interviewees were also asked what strategies they used for completing this test. Other interviewees depended on previously mentioned tactics, such as focusing on the title and wording without being presented with the source. Interviewees \#1, \#2, and \#5 all remarked that they depended on their previous knowledge about current events more than these tactics. This implies that those who engage with news more, regardless of background, gain a more profound knowledge and stronger media literacy about the news that can be used to make these differentiations.

Altogether, the results appear to be applicable to a larger population, as those who engaged with news the least received a composite score of fifty percent. Even so, interviewing and testing a larger number of people would ensure greater external validity. Since the researcher interviewed family and friends, there may have been some social desirability bias in the responses, but an avoidance of bias and a maintenance of composure on the researcher's part lessened the chance of this occurring. Questions were standardized with all interviewees, each living within the same media market. The liberal bias of all interviewees could have potentially affected results, even though this highlighted some important findings about engagement with partisan media. Nonetheless, these possible biases are not enough to interfere with the connection between the frequency at which news is engaged with and possessing a larger skill set to recognize fake news. As evidenced by this data, knowing what is going on around the world is not rooted in disadvantage. 


\section{Appendix:}

\section{Interview Questions}

Do you consider yourself to be a politically active and civically engaged person?

When was the last time you voted?

How often do you engage with the news?

Where do you typically get your news from? Sources? Local news?

Is social media one of the primary ways that you get your news?

Do you usually engage with news that does not support your beliefs?

What does the term fake news mean to you? How prevalent do you think it is? Where are you most likely to encounter it?

How do you figure out whether or not a news story is trustworthy?

Have you ever fallen subject to fake news? What about it drew you in?

Did you use any tactics to discern the difference between real and fake news? Do you depend more on media literacy (ability to critically evaluate media), your knowledge/awareness of news stories, or both? Does visualization play a role? 


\section{Fake News Test}

Climate Change can be Stopped by Turning Air Into Gasoline (The Atlantic)

https://www.theatlantic.com/science/archive/2018/06/its-possible-to-reverse-climate-change-sug gests-major-new-study/562289/

Two Peacocks that Escaped Philadelphia Zoo Found, Search for Last Continues (Philly.com) http://www.philly.com/philly/news/pennsylvania/philadelphia/philadelphia-zoo-peacocks-escape -76-highway-20180531.html

Social Security Now Called 'Federal Benefit Payment' (viral Facebook article) https:/www.snopes.com/fact-check/federal-benefit-payments/

Pope Francis Shocks World, Endorses Donald Trump for President (WTOE 5 News)

https://www.snopes.com/fact-check/pope-francis-donald-trump-endorsement/

Jet-Powered Suit Sets New Fastest Speed as World Records Tumble (NBC News)

https://www.nbcnews.com/video/new-guinness-world-records-set-for-longest-basketball-shot-jet suit-speed-1092096067874

Trump Admin Expected to Suspend August US-South Korea Military Drill as Pentagon Scrambles (CNN) https://www.cnn.com/2018/06/13/politics/us-korea-military-drills/index.html

Sessions Defends Separating Immigrant Families by Citing Senate Confirmation Vote (The Onion)

https://politics.theonion.com/sessions-defends-separating-immigrant-families-by-citin-18268720 $\underline{58}$

Trump Answers Kim Kardashian’s Clemency Plea (Fox News)

http://video.foxnews.com/v/5794380038001/?\#sp=show-clips

Pope Endorses Bernie Sanders for President (National Report)

https:/www.snopes.com/fact-check/pope-francis-endorses-bernie-sanders/

George H.W. Bush Hospitalized One Day After the Funeral for his Wife, Barbara (Washington Post)

https://www.washingtonpost.com/news/politics/wp/2018/04/23/george-h-w-bush-hospitalized-th e-day-after-funeral-for-his-wife-barbara/?utm term $=.5559181 \mathrm{f} 551 \mathrm{a}$ 


\section{NOTES}

${ }^{1}$ McKernon, Edward. "Fake News and the Public: How the Press Combats Rumor, the Market Rigger, and the Propagandist.” Harper's Monthly, June 1925.

${ }^{2}$ Kurtzleben, Danielle. “Did Fake News on Facebook Help Elect Trump? Here's What We Know,” NPR. Last modified April 11, 2018.

https:/www.npr.org/2018/04/11/601323233/6-facts-we-know-about-fake-news-in-the-2016-election

${ }^{3}$ Vosoughi, Soroush, Deb Roy, and Sinan Aral. "The Spread of True and False News Online.” Science 359 , no. 6380 (2018): 1146-1151.

${ }^{4}$ Stroud, Natalie Jomini. Niche News: The Politics of News Choice. New York: Oxford University Press, 2011. 